\title{
Hereditary leiomyomatosis and renal cell cancer syndrome
}

\author{
Togas Tulandi MD MHCM, William D. Foulkes MBBS PhD
}

See also www.cmaj.ca/lookup/doi/10.1503/cmaj.109-4962

Competing interests: Togas Tulandi is an advisor for Actavis Inc. No other competing interests were declared.

This article has been peer reviewed.

The authors have obtained patient consent.

Affiliations: Departments of Obstetrics and Gynecology (Tulandi) and Medical Genetics (Foulkes), McGill University; and Jewish General Hospital (Foulkes), Montréal, Que.

Correspondence to: Togas Tulandi, togas.tulandi@mcgill.ca CMAJ 2016. DOI:10.1503 /cmaj.150191

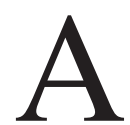
30-year-old woman was referred to the reproductive unit of the McGill University Health Centre for consultation about fertility and uterine myomata. She complained of swelling and pain in her abdomen that had lasted for one year, and reported that bumpy, hyperpigmented lesions had started to appear on her skin in her early $20 \mathrm{~s}$. The patient reported that the lesions were more painful in the cold weather and had been spreading. The patient's aunt had a history of uterine leiomyosarcoma, cutaneous leiomyomata and a renal cyst; the patient's mother had undergone a hysterectomy for uterine fibroids and also had a history of cutaneous leiomyomata.

Multiple firm, tender and indurated erythematous papules and nodules were found on the patient's chest, back, arms and legs during physical examination (Figure 1). The uterus was 18 gestational weeks in size. Biopsy of the skin lesion indicated cutaneous leiomyoma. Computed tomography and magnetic resonance imaging showed
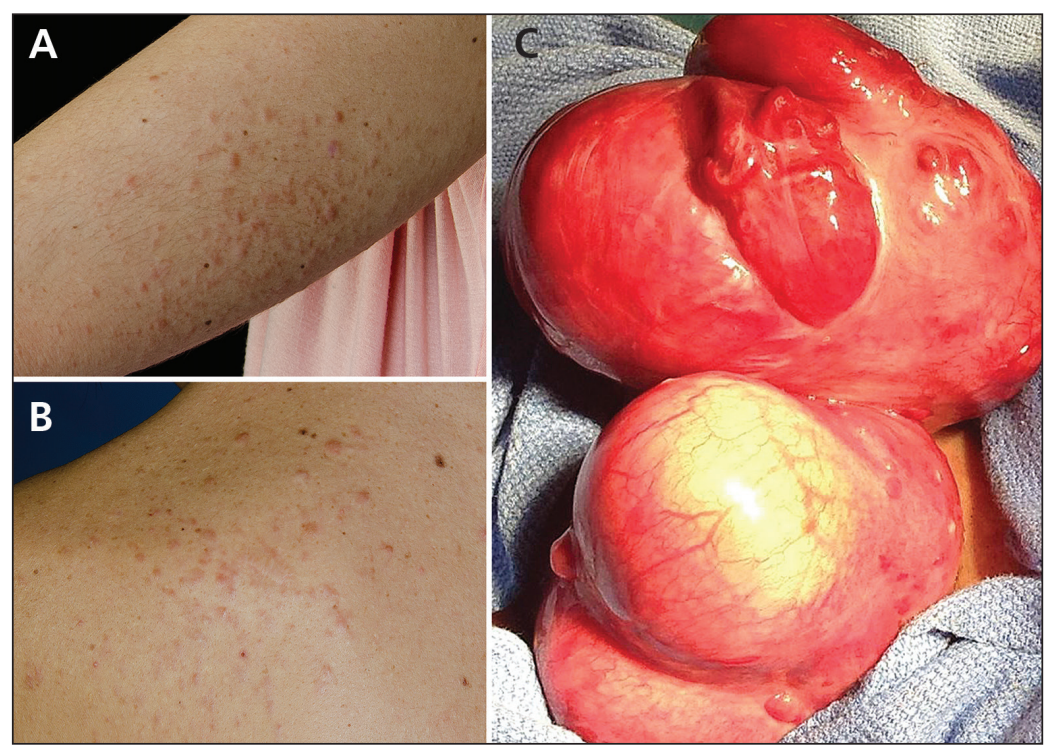

Figure 1: Cutaneous leiomyomata on the arm (A) and back (B) of a 30-year-old woman presenting with uterine myomata (C). Genetic testing showed a mutation in the patient's fumarate hydratase gene, consistent with autosomal dominant hereditary leiomyomatosis and renal cell cancer syndrome. uterine myomata, a right renal cyst and left adrenal adenoma. Genetic testing showed a substitution mutation (thymine for cytosine) at position 139 of the coding sequence (c.139 C > T) of the fumarate hydratase $(F H)$ gene, predicted to result in a truncated protein (p.Gln47Stop). This mutation is consistent with autosomal dominant hereditary leiomyomatosis and renal cell cancer syndrome. ${ }^{1,2}$ The patient underwent myomectomy by laparotomy; the largest myoma was $6 \times 11 \times 11 \mathrm{~cm}$ (Figure 1). Histopathology showed atypical leiomyoma.

Hereditary leiomyomatosis and renal cell cancer syndrome is uncommon, ${ }^{1,2}$ and its prevalence is unknown. Because genetic testing is required to confirm a clinical suspicion of this condition, it is likely underdiagnosed. In a series of 54 women with $\mathrm{FH}$ mutation, 5 had leiomyosarcoma before the age of 40 years and 4 had atypical leiomyoma, ${ }^{2}$ in contrast to a prevalence of $0.08 \%-0.13 \%$ for leiomyosarcoma among women with myoma who are less than 50 years of age. ${ }^{3}$

The underlying mutation appears to promote malignant transformation of leiomyoma at a young age. Thus, morcellation of myoma in women with this syndrome is not recommended. Morcellation of an undiagnosed malignant growth may lead to spreading of the cancerous cells inside the abdominal cavity. Thus, as in this patient's case, removal of the myoma by laparotomy is best. Follow-up consists of surveillance with imaging and early intervention as needed.

The presence of cutaneous leiomyomata could be a marker for internal malignant disease and should alert the physician to hereditary leiomyomatosis and renal cell cancer.

\section{References}

1. Tomlinson IP, Alam NA, Rowan AJ, et al. Germline mutations in FH predispose to dominantly inherited uterine fibroids, skin leiomyomata and papillary renal cell cancer. Nat Genet 2002;30:406-10.

2. Lehtonen HJ, Kiuru M, Ylisaukko-Oja SK, et al. Increased risk of cancer in patients with fumarate hydratase germline mutation. J Med Genet 2006;43:523-6.

3. Mao J, Pfeifer S, Zheng XE, et al. Population-based estimates of the prevalence of uterine sarcoma among patients with leiomyomata undergoing surgical treatment. JAMA Surg 2015; 150:368-70. 